\title{
Factors Affecting Incomes of Watershed Dairy Households in Srikakulam District of Andhra Pradesh - Econometric Analysis
}

\author{
P. V. R. M. Reddy ${ }^{1 *}$, M. Girija Shankar ${ }^{1}$, B. Janardhan Reddy ${ }^{1}$, Y. Shankar Naik ${ }^{1}$, \\ R. V. Ramana ${ }^{2}$, D. V.S. R. L. Rekha ${ }^{2}$ and Y. Eswara Prasad ${ }^{2}$ \\ ${ }^{1}$ Director (WS), ${ }^{2}$ Commissioner, ${ }^{3}$ Joint Commissioner (WS), ${ }^{4}$ State Technical Expert \\ (Forestry), O/o SLNA, PR\&RD Department, Tadepalli, Andhra Pradesh, India. \\ Chief Engineer", Chief ${ }^{6}$, Consultant (Agriculture Economist) ${ }^{7}$, WAPCOS Limited, Hyderabad, \\ Telangana State, India \\ *Corresponding author
}

\section{A B S T R A C T}

Keywords

Jersy crossbred, Dairy farming, regression coefficients,

Decomposition analysis

Article Info

Accepted:

20 June 2021

Available Online:

10 July 2021
The resource use efficiency of dairy animals (jersy and desi) in contributing to the net income of the watershed households in Srikakulam district of Andhra Pradesh was assessed through Cobb- Douglas production function and further decomposed to find out the income difference between jersy and desi milch animals into its constituent sources through Cobb-Douglas production function and decomposition analysis. The significant regression co-efficents found to be were number of dairy animals and labour cost for desi while cost on concentrates was the only variable in jersy crossbred cows contributing to incomes of the dairy farmers. The decomposition analysis revealed that the overall change in net income was guided by the gap attributable to the relative change in resource use to an extent of 0.8782 per cent and the incomes may be further enhanced by proper utilization of watershed interventions in the hilly region of the selected area.

\section{Introduction}

Milk production in India has increased from 17.0 MT (million tonnes) in 1950-51 to 104.8 MT in 2007-08 and further increased to 187.7 MT in 2018-19. While the per capita availability during the same period indicated the enhanced trend from $124 \mathrm{gms} /$ day in 195051 to $252 \mathrm{gms} /$ day in $2007-08$ and finally to 394 gms/day in 2018-19 (Basic Animal Husbandry Statistics, DAHD\&F, GoI). The performance of Indian dairy sector is remarkable specially after launching of "Operation Flood" programme in 1970. Moreover, the growth in milk production was achieved through extensive intervention by the Indian Government, as well as through increased demand driven by population growth, higher incomes and urbanization (Candler and Kumar, 1998). However, it is still below the world average of 285 gms/day. Nevertheless, the livestock income has been a reliable source of income for the livelihood of the resource poor farmer households. Dairy 
sector plays an important role in generating income and employment, augmenting income of marginal farmers and landless households/labourers as well as meeting nutritional requirement. In the country about three fourths of the farmers are marginal and small in terms of land holding.

In Andhra Pradesh state the milk production increased from 5814 ('000 tonnes) during 2001-02 to 15044 ('000 tonnes) in 2018-19 and at the same time the per capita availability of milk showed a shift from 209 gms/day to $623 \mathrm{gms} /$ day during the same period (Chief Planning Officer, Srikakulam 2019-20). The growth sector has been identified as one of the "Growth Engines" in the state. The projected milk production by $2021-22$ is 254.5 MT as per the vision 2022 document. Moreover, dairy activity is a major supplementary livelihood to small, marginal and landless farmers.

An important feature of milk production system in drought prone areas of the state is that dairy farming is not considered as an ambitious profession. In other words, the dairy farmers are producing milk at a subsistence level and they do not treat this activity as a profitable one. Yet small and marginal farmers and landless poor are contributing about $62 \%$ of total milk production and own $70 \%$ of livestock in Andhra Pradesh and women population provides nearly $60 \%$ of livestock farming labour (Govt. of Andhra Pradesh 2019, Socio-Economic Survey 2018- 19, Planning Department, Govt. of Andhra Pradesh).

Despite significant increase in irrigated area in India during the planned development of over five decades, about $60 \%$ of net sown area in the country is still rainfed (Bhatia, 2005). In order to increase area under rainfed conditions the Govt. of India has been implementing the developmental programmes. One of such programmes is an Integrated Watershed Management approach which is found to be an appropriate solution. Keeping all these in view, the Govt. of India initiated a special programme "PMKSY-Watersheds" erst while IWMP (Integrated Water Management Programme) as one of the developmental programmes in drought prone or semiarid regions as majority of the area is covered under rainfed situations (Govt of India-2011). The Department of Land Resources (DoLR), under the Ministry of Rural Development (MoRD), has been implementing this programme since 2009. In Andhra Pradesh, the Department Panchayat Raj \& Rural Development through the State Level Nodal Agency (SLNA) is implementing 372 watershed projects with an outlay of Rs. 1985.16 crores covering an extent of 15.83 lakh hectares in five batches from 2009-10 to 2013-14.

Under this programme, one of the components is to increase the incomes of the watershed beneficiaries through dairy sector by providing animal health camps, improved cattle, artificial insemination, feed supply etc., It is in this context the present study is undertaken to assess the economic impact of resource use efficiency of local or native breeds as well as improved or cross breed milch animals pertaining to small and marginal farm households.

Keeping this in view the objectives of the present study are to:

To analyse the factors affecting the net income of the jersy and desi animals in the watershed region

To decompose the contribution of resources to the net income differences between the jersy and desi dairy animals. To suggest the policy implications in the watershed region of Srikakulam district of Andhra Pradesh. 


\section{Materials and Methods}

Srikakulam district of Andhra Pradesh state was selected purposively as this happens to be the only district in North-Coastal Zone where Batch-IV (2012-13) projects of PMKSYWatersheds have been in operation and completed the project period. The Batch-IV projects have been implemented in three watershed areas namely Addangi, Manda and Joduru consisting of 7, 11 and 16 microwatershed villages respectively. The primary data pertaining to dairy animals was collected from marginal, small and landless households who possess local (desi) or native (indigenous) and improved (graded or cross breeds or jersy) breeds on costs, returns and use of inputs (factors or resources) by survey method through pre-tested questionnaire.

\section{Study area/ Sample selection}

Multi stage sampling technique was adopted in the present study in obtaining the relevant data in order to achieve the stated objectives from the households having desi and jersy dairy animals separately. Thus, the necessary information was collected randomly from a sample of 41 desi (native cows and shebuffalos) and 33 jersy cows households constituting a total of 74 respondents covering all the three watershed projects for the period 2019-20. Further, the data collected was analysed by applying suitable statistical techniques i.e., log-log linear production function (Cobb-Douglas production function) duly adopting Ordinary Least Square (OLS) estimation procedure. The study also compares the regression co-efficients between local and jersy breeds using the decomposition method formulated by Bisaliah (1977). In order to find out the contribution of watershed dairy activities on inputs use differences from the total net income differences between the jersy and desi dairy households the following double linear production function was applied.

$$
Y=A N \beta 1 \text { F } \beta 2 \text { C } \beta 3 \text { L } \beta 4 \text { O } \beta 5 \text { ei ---> (1) }
$$

Where $\mathrm{Y}=$ Net income from dairy activity of a household (Rs) N=Number of animals owned (Number)

$\mathrm{F}=$ Total amount spent on dry and green fodder (Rs)

$\mathrm{C}=$ Amount spent on concentrates

$\mathrm{L}=$ Amount spent on labour (Rs)

(Rs)

$\mathrm{O}=$ Other costs including insurance, health etc., (Rs) ei=error term or random disturbance term

$\beta 1$ to $\beta 5$ are the respective regression coefficient parameters. $A=$ Scale parameter or intercept

The equation (1) in the form of logarithm becomes as:

$\log \mathrm{Y}=\log \mathrm{A}+\beta 1 \log \mathrm{N}+\beta 2 \log \mathrm{F}+\beta 3 \log \mathrm{C}+$ $\beta 4 \log \mathrm{L}+\beta 5 \log \mathrm{O}+\mathrm{e}--------->(2)$

For the present analysis, two types (i.e., one for jersy and another for desi mulch animals) of Cobb-Douglas production functions are required in order to assess the factors responsible for contributing to net income of the households as well as decomposition of the inputs during the study period. Thus the two production functions in logarithmic forms:

$\log \mathrm{Y} 1=\log \mathrm{A} 1+\beta 1 \log \mathrm{N} 1+\beta 2 \log \mathrm{F} 1+\beta 3$ $\log \mathrm{C} 1+\beta 4 \log \mathrm{L} 1+\beta 5 \log \mathrm{O} 1+\mathrm{e} 1$-------$>$ (3)

For jersy breed $\log \mathrm{Y} 2=\log \mathrm{A} 2+\alpha 1 \log \mathrm{N} 2+$ $\alpha 2 \log \mathrm{F} 2+\alpha 3 \log \mathrm{C} 2+\alpha 4 \log \mathrm{L} 2+\alpha 5 \log \mathrm{O} 2+$ e2 ---------> (4)

For desi animals Definitions of variables and parameters in (3) and (4) are the same as in (1). 
Considering differences between equations (3) and (4), performing slight algebraic manipulations and re-arranging some terms the final decomposition model is:

$\left[\begin{array}{llll}\log & \mathrm{Y} 1-\log & \mathrm{Y} 2\end{array}\right]=\left[\begin{array}{lll}\log & \mathrm{A} 1-\log & \mathrm{A} 2\end{array}\right]+[\log$ $\mathrm{N} 1(\beta 1-\alpha 1)+\log$ F1 $(\beta 2-\alpha 2)+\log \mathrm{C} 1 \quad(\beta 3-$ $\alpha 3)+\log$ L1 $(\beta 4-\alpha 4)+\log \mathrm{O}(\beta 5-\alpha 5)]+[\beta 1(\log$ $\mathrm{N} 1 / \log \mathrm{N} 2)+\beta 2(\log \mathrm{F} 1 / \log \mathrm{F} 2)+\beta 3(\log \mathrm{C} 1 / \log$ $\mathrm{C} 2)+\beta 4(\log \quad \mathrm{L} 1 / \log \quad \mathrm{L} 2)+\beta 5(\log \quad \mathrm{O} 1 / \log$ O2) $]+[(\mathrm{e} 1-\mathrm{e} 2)]--->(5)$

The decomposition equation (5) involves decomposing the natural logarithm of the ratio of net income derived from watershed activities to the net income obtained by farmers practices (desi animals). It is approximately a measure of percentage change in net income with the project interventions. The left hand side of the equation is a measure of percentage change in net income due to shift in scale parameter (A) of the production function. The first bracketed term on the right hand side, the difference between the natural logarithms of the constant terms, is the gap attributable to the neutral technology gap. The second bracketed term is the gap attributable to the non-neutral component of the technology by input use for desi households. Thus it is an expression of the non-neutral technology gap after adjusting for the level of input use in the jersy and desi dairy households. The third bracketed term refers to the gap attributable to the difference in input use by the slope co-efficient of the net income function fitted for jersy owners of the watershed programme. It is the gap in input use between jersy and desi households after adjusting for income elasticities of different inputs considered i.e., number of animals, fodder, concentrates, labour and other costs in the model.

The last component is the random error term, which the model could not consider (Bisaliah 1977). Further the co-efficient of multiple determination (R2) and adjusted R2 ( $\overline{R 2})$ were also calculated to test the fitness of the model selected for the study.

\section{Results and Discussion}

\section{Desi Animals}

The estimated production function for desi varieties is presented in Table-1. The coefficient of multiple determination (R2) and adjusted R2 explained $91.95 \%$ and $90.80 \%$ respectively variation in net income of desi animals due to variation in all the resources included in the function put together showing a better fit of the model. The effect of intercept (constant term) was high and significant at $1 \%$ level of probability indicating that the selected area is a hill region and local indigenous animals more over have high disease resistance capacity and more unproductive life period compared to cross breeds. The production elasticity co-efficients of number of animals and costs on labour were positive and significant at $1 \%$ and $5 \%$ level of probability respectively which shows that one percent increase in the number of animals and labour cost would increase by 0.7843 per cent and 0.1966 per cent respectively, at ceteris paribus.

On the other hand, the elasticity co-efficients of concentrates and miscellaneous (other) costs were positive and non-significant explaining their contribution to net income to an extent of 0.0349 per cent and 0.0511 per cent increase for every one per cent additional use of these inputs. The fodder regression coefficient was negative and non-significant indicating the decrease in the net income for one per cent increase in the use of this input.

The sum of regression co-efficients however indicated almost constant returns to scale (0.96) in the watershed areas for desi dairy animals. 


\section{Jersy cows}

Table- 2 presents the estimates of jersy cows production function in the selected watershed region.

A perusal of the table revealed that the coefficients of all the selected variables except other costs were positive indicating contribution to net income increase of jersy households.

Among these, the parameter on amount spent towards dry and green fodder was significant implying that for every one percent increase in dry and green fodder expenditure the net income would increase by 0.4635 per cent.

Further, it could be noticed that the elasticities of all the inputs totally were more than unity (1.0716) thus indicating increasing returns to scale. The adjusted co-efficient of multiple determination $(\overline{R 2})$ was $89.88 \%$ showing fairly a high degree of goodness of fit.

Decomposition analysis of net income between jersy and desi households

Under the decomposition model, the income difference between jersy and desi animals was decomposed into its constituent sources and the results are furnished in Table-3.

An examination of the results of decomposition analysis revealed that there was not much discrepancy between the observed change $(1.0727 \%)$ and the actual estimated difference $(1.0728 \%)$ in the net incomes of jersy and desi dairy households in the watershed region of Srikakulam district of Andhra Pradesh State. That means the model fits well and represents the maintenance of milch cattle of the entire study location. This indicates jersy cows have higher income by 1.0727 per cent than desi animals because desi units are bigger in scale parameter compared to jersy. However, technologically jersy breeds maintenance are superior than desi animals.

The overall change is attributed to the relative change in input use weighted by the slope coefficient of the function i.e., $0.8782 \%$ in the present study which indicates jersy cows owners use higher inputs compared to desi animals households. (Biswajit Mondal, 2015).

The present study indicates that the impact of watershed interventions was negligible for the time being as the neutral and non-neutral technological change supersede each other and nullify the effect on net income. These results are inconformity with the study conducted by Soumitra Chatterjee et al., (2020).

As the selected projects have completed the implementation period by the end of 2019-20, hence the effect of change in technology on net incomes is marginal $(0.19 \%)$.

The negative impact of neutral technological change under constant returns to scale was superseded by the positive input of the nonneutral technological change under varying returns to scale of all inputs applied.

Thus it is evident that the overall change in net income was guided by the gap attributable to the relative change in input use to an extent of 0.8782 per cent and the incomes may be further enhanced by better utilization of watershed interventions implemented by the project implementing agency in the drought prone areas of Srikakulam district during the project period. 
Table.1 Determinants of local dairy animals Net income

\begin{tabular}{|c|c|c|c|c|}
\hline S.No. & Parameters & $\begin{array}{c}\text { Regression co- } \\
\text { efficients }\end{array}$ & $\begin{array}{c}\text { Standard } \\
\text { Error }\end{array}$ & $\begin{array}{c}\text { 't' } \\
\text { value }\end{array}$ \\
\hline $\mathbf{1}$ & Intercept & 9.0639 & 2.5499 & $\mathbf{3 . 5 5 5} * *$ \\
\hline $\mathbf{2}$ & Number of dairy animals & 0.7843 & 0.2741 & $\mathbf{2 . 8 6 1} * *$ \\
\hline $\mathbf{3}$ & Value of dry and green fodder & -0.1031 & 0.1197 & $\mathbf{- 0 . 8 6 1}$ \\
\hline $\mathbf{4}$ & Cost of concentrates & 0.0349 & 0.1754 & $\mathbf{0 . 1 9 9}$ \\
\hline $\mathbf{5}$ & Labour costs & 0.1966 & 0.0850 & $\mathbf{2 . 3 1 3}$ \\
\hline $\mathbf{6}$ & Other costs & 0.0511 & 0.0669 & $\mathbf{0 . 7 6 5}$ \\
\hline $\mathbf{7}$ & Co-efficient of multiple determination & 0.9195 & & \\
\hline $\mathbf{8}$ & Adjusted $\mathrm{R}^{2}\left(\boldsymbol{R}^{\mathbf{R}}\right)$ & 0.908 & & \\
\hline $\mathbf{9}$ & Sum of regression co-efficient $\left(\sum \mathbf{b i}\right)$ & $\mathbf{0 . 9 6 3 8}$ & & \\
\hline
\end{tabular}

** Significant at $1(\mathrm{p}=0.01)$ and $5(\mathrm{p}=0.05)$ per cent level of probability

* Significant at $5(\mathrm{p}=0.05)$ per cent level of probability.

Table.2 Determinants of Net income of jersy breeds

\begin{tabular}{|c|c|c|c|c|}
\hline S.No. & Parameters & $\begin{array}{c}\text { Regression co- } \\
\text { efficients }\end{array}$ & $\begin{array}{c}\text { Standard } \\
\text { Error }\end{array}$ & $\begin{array}{c}\text { ' } \mathbf{t} \\
\text { value }\end{array}$ \\
\hline $\mathbf{1}$ & Intercept & 3.3505 & 5.6835 & $\mathbf{0 . 5 9 0}$ \\
\hline $\mathbf{2}$ & Number of dairy animals & 0.2344 & 0.5790 & $\mathbf{0 . 4 0 5}$ \\
\hline $\mathbf{3}$ & Value of dry and green fodder & 0.4635 & 0.2255 & $\mathbf{2 . 0 5 *}$ \\
\hline $\mathbf{4}$ & Concentrates cost & 0.0759 & 0.3732 & $\mathbf{0 . 2 0 3}$ \\
\hline $\mathbf{5}$ & Labour costs & 0.3216 & 0.2862 & $\mathbf{1 . 1 2 4}$ \\
\hline $\mathbf{6}$ & Other costs & -0.0238 & 0.1775 & $\mathbf{- 0 . 1 3 4}$ \\
\hline $\mathbf{7}$ & Co-efficient of multiple determination & 0.9147 & & \\
\hline $\mathbf{8}$ & Adjusted R2 $(\vec{R})$ & 0.8989 & & \\
\hline $\mathbf{9}$ & Sum of regression co-efficients $(\boldsymbol{\Gamma} \mathbf{b i})$ & $\mathbf{1 . 0 7 1 6}$ & & \\
\hline
\end{tabular}

* Significant at $5(\mathrm{p}=0.05)$ per cent level of probability.

Table.3 Decomposition Analysis of Net income between jersy and desi activities/practices

\begin{tabular}{|c|c|c|}
\hline S.No & Item & Difference between jersy and desi practices \\
\hline $\mathbf{1}$ & Total observed change in Net Income & $\mathbf{1 . 0 7 2 7}$ \\
\hline $\mathbf{2}$ & Sources of change & $\mathbf{0 . 1 9 4 6}$ \\
\hline & a. Neutral technological gap & $\mathbf{- 5 . 7 1 3 3}$ \\
\hline $\mathbf{3}$ & b. Non-neutral technological gap & $\mathbf{5 . 9 0 7 9}$ \\
\hline $\mathbf{4}$ & Input changes & $\mathbf{0 . 8 7 8 2}$ \\
\hline
\end{tabular}

The constant term in the case of desi animals was higher than that for the jersy cows incomes which virtually signifies that there was little impact of the project interventions and it may require some more time to indicate the upward shift in the production function due to PMKSY-Watershed project activities. Hence, there is a need to assess the implementations of jersy crossbreed animals in the selected watershed projects periodically/overtime in a long run perspective and rectify the corrections if any. 


\section{Policy implications}

Government can play a crucial role in providing service explaining new ways of production and promoting the use of relevant suitable fodders and artificial insemination to increase farm level profitability of milk production,

Create the necessary incentives for dairy households to scale up their dairy activities in order to augment their incomes and thus helping in doubling the incomes of the farmers

Artificial insemination and health camps may be conducted periodically and provide the facilities for more involvement of the households in these programmes

Awareness camps may be organized in the watershed villages regarding the beneficial effects of use of concentrates, medical insurance etc., for increasing the resource use efficiency as the sample respondents are landless, marginal and small households

There is a need to provide the vast majority of small scale dairy farmers with quality livestock services packaged that are affordable and have maximum impacts on the key production and economic factors of dairy farms.

\section{References}

Basic Animal Husbandry Statistics-2019, Department of Animal Husbandry and Dairying, Ministry of Fisheries, Animal Husbandry \& Dairying,
Government of India

Bhatia, M. S., 2005. "Viability of Rainfed Agriculture in Semi Arid Regions" NABARD Occasional Paper No. 40.

Bisaliah, S., 1977. "Decomposition Analysis of Output Change Under New Production Technology in Wheat Farming: Some Implications to Returns on Research Investment," Indian Journal of Agricultural Economics, Indian Society of Agricultural Economics, vol. 32(3), 193-201.

Candler, W., \& Kumar, N. (1998). India: the dairy revolution: the impact of dairy development in India and the World Bank's contribution. World Bank.

Chatterjee, Soumitra \& Chakraborty, Riya \& Banerjee, Hirak. (2020). Economic impact assessment of conservation agriculture on small and marginal farm house holds in eastern India. Agricultural Economics Research Review. 33. 127-138. 10.5958/09740279.2020.00024.5.

Chief planning officer - Hand Book of statistics - 2019-20, Srikakulam District Government of Andhra Pradesh 2019, Socio-Economic Survey Government of India, 2011 Socio-Economic Survey

Mondal, Biswajit, N. Loganandhan, K. K. Reddy and K., Channabasappa. (2015). Decomposition analysis of output change under watershed management interventions in semi-arid regions. Indian Journal of Soil Conservation. 43. 110-114.

\section{How to cite this article:}

Reddy, P. V. R. M., M. Girija Shankar, B. Janardhan Reddy, Y. Shankar Naik, R. V. Ramana, D. V. S. R. L. Rekha and Eswara Prasad, Y. 2021. Factors Affecting Incomes of Watershed Dairy Households in Srikakulam District of Andhra Pradesh - Econometric Analysis. Int.J.Curr.Microbiol.App.Sci. 10(07): 689-695. doi: https://doi.org/10.20546/ijcmas.2021.1007.075 